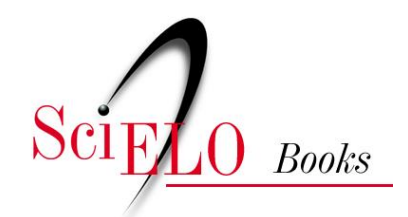

\title{
Desenvolvimento e cultura
}

Parâmetros para a reflexão dessa complexa relação

\author{
Cláudia Ribeiro Pfeiffer
}

\section{SciELO Books / SciELO Livros / SciELO Libros}

PFEIFFER, CR. Desenvolvimento e cultura: parâmetros para a reflexão dessa complexa relação. In BRASILEIRO, MDS., MEDINA, JCC., and CORIOLANO, LN., orgs. Turismo, cultura e desenvolvimento [online]. Campina Grande: EDUEPB, 2012. pp. 151-168. ISBN 978-85-7879-194-0. Available from SciELO Books < http://books.scielo.org>.

\section{(c) (1) @()}

All the contents of this work, except where otherwise noted, is licensed under a Creative Commons Attribution-Non Commercial-ShareAlike 3.0 Unported.

Todo o conteúdo deste trabalho, exceto quando houver ressalva, é publicado sob a licença Creative Commons Atribuição Uso Não Comercial - Partilha nos Mesmos Termos 3.0 Não adaptada.

Todo el contenido de esta obra, excepto donde se indique lo contrario, está bajo licencia de la licencia Creative Commons Reconocimento-NoComercial-CompartirIgual 3.0 Unported. 


\title{
Desenvolvimento e cultura: parâmetros para a reflexão dessa complexa relação
}

\author{
Cláudia Ribeiro Pfeiffer
}

\section{Introdução}

Esse texto, de caráter exploratório, tem por finalidade apresentar subsídios que contribuam para fundamentar a construção de posicionamentos teóricos, criteriosos, sobre a complexa relação entre desenvolvimento e cultura. Especificamente, sobre a necessidade e as possibilidades de desenvolvimento em locais ainda não inseridos, de forma competitiva, nos espaços econômicos globais; ou, em outros termos, em locais nos quais, a(s) "cultura"(s) não esteja(m) completamente submetida(s) à lógica capitalista.

Ele é produto de reflexões desencadeadas a partir do debate acadêmico, internacional e nacional, sobre as possibilidades e limites de desenvolvimento econômico local, em contexto de 
globalização da economia. Debate que pode ser sintetizado nas seguintes posições:

- As economias locais só podem ser encaradas como malhas de uma rede econômica global, sem qualquer realidade própria fora desse contexto (AMIN E ROBINS, 1994).

- Existe uma heterogeneidade importante no sistema econômico mundial. Enquanto algumas frações ou segmentos do sistema possuem uma forte vinculação com um núcleo globalizado internacional, outras frações e segmentos - ou circuitos de obtenção de excedentes econômicos - possuem tão-somente uma vinculação limitada, muito reduzida ou nula, sendo sua lógica de funcionamento muito distinta (economia camponesa, economia de subsistência, o setor informal ou as pequenas empresas de âmbito local ou regional). Em sendo assim, a via tradicional do desenvolvimento concentrador e urbano-industrial não deixou de ocorrer, mas outras vias de desenvolvimento econômico passaram a existir. (LLORENS, 2001)

- Há uma grande variedade de produção não capitalista no mundo. Experiências que se fundamentam e se caracterizam por valores e práticas nas quais predominam os princípios da igualdade, da solidariedade e do respeito à natureza e não por valores e práticas que produzem: desigualdades de recursos e de poder; formas de sociabilidade empobrecidas, reduzidas ao intercâmbio e ao benefício pessoal produzido pelas relações de concorrência; esgotamento dos recursos naturais. (SANTOS, 2005). 
A autora parte do pressuposto de que um posicionamento criterioso sobre as necessidades e/ou possibilidades de desenvolvimento - e não apenas de desenvolvimento econômico - em locais com as características acima destacadas, passa pela explicitação do que se entende por cultura e desenvolvimento, vocábulos polissêmicos. E no sentido de contribuir para sua construção, apresenta: (i) conceitos de cultura e concepções de desenvolvimento, presentes na literatura sobre o tema; (ii) os conceitos de cultura e desenvolvimento que adota em suas reflexões; (iii) seu posicionamento atual em relação ao assunto. Antes, porém, cabe explicar porque considera relevante a construção desses posicionamentos.

\section{Empresariamento urbano e "empresariamento cultural": 0 avanço perigoso dessas estratégias de promoção do desenvolvimento local no Brasil}

Desde o início da década de 90, quando os governos dos municípios brasileiros começam a experimentar a autonomia conquistada com a Constituição de 1988, uma série de estratégias, até então não experimentadas no país, vem sendo adotadas por eles no sentido de ampliar a democracia, melhorar a atividade governamental, resolver problemas e promover desenvolvimento. Dentre elas, destacam-se as estratégias que podemos denominar de ativismo democrático, "empreendedorismo governamental” e empresariamento urbano.

$\mathrm{O}$ ativismo democrático consiste na atitude governamental em relação à administração urbana, orientada pela concepção de que é preciso alargar, radicalizar a democracia e a cidadania, em termos políticos e econômicos, por meio de: construção de espaços de participação popular na gestão local 
ou, em outros termos, de novas esferas públicas de exercício da cidadania e de controle sobre o Estado; direcionamento para demandas sociais, através da inversão de prioridades das políticas municipais, ou seja, do atendimento de demandas populares mais imediatas e localizadas; democratização das informações e do acesso aos bens e serviços públicos; construção de uma nova cultura política (FEDOZZI, 1997).

O "empreendedorismo governamental" caracteriza-se por atitudes em relação à administração urbana, orientadas pela concepção de que os governos devem ser empreendedores, inovadores, imaginosos, criativos, para melhorar a atividade governamental. O que significa: governos dispostos a abandonar velhos programas e métodos e a assumir riscos; a transformar funções da cidade em fontes de receita; a trabalhar de acordo com o setor privado; a privatizar-se e orientar-se para o mercado; a focalizar a avaliação de desempenho das suas ações. Sobretudo, mediante: promoção da competição entre os que prestam serviços; transferência das atividades da burocracia para cidadãos; avaliação da atuação das agências em função dos resultados; orientação por objetivos e não por regulamentos e regras; redefinição dos usuários como clientes (oferta de opções); oferta de serviços a guisa de correção ou remédio; investimento na produção de recursos para as despesas; promoção do gerenciamento com participação; preferência por mecanismos de mercado a soluções burocráticas; catalisação dos setores público, privado e voluntário para a ação conjunta na resolução de problemas comunitários. (OSBORNE E GAEBLER, 1995)

O empresariamento urbano pode ser apresentado como um comportamento empresarial adotado por coalizóes de forças que se formam nas cidades, para tentar atrair fontes 
externas de financiamento, novos investimentos diretos ou novas fontes geradoras de emprego, no sentido de tornar as cidades mais atrativas para o desenvolvimento capitalista. Nessa estratégia, o governo e a administração urbana desempenham um papel de agilizadores dos interesses estratégicos desse desenvolvimento. Sua implementação se realiza por meio de iniciativas voltadas para: explorar vantagens específicas para a produção de bens e serviços (recursos básicos, localização ou vantagens criadas através de investimentos públicos e privados e de subsídios); transformar a cidade em lugar inovador, excitante, criativo e seguro para viver, visitar, jogar e consumir; transformar a cidade em local de controle e funções de comando de altas operações financeiras, de governo ou de centralização e processamento; assegurar a sobrevivência da cidade através da captura/manutenção de repasses dos governos centrais (HARVEY, 1996).

Ainda que as três estratégias continuem sendo adotadas nos diversos municípios brasileiros, pode-se afirmar que a lógica do empresariamento urbano avança por todo o país, tentando se impor em atividades econômicas, regióes e locais, até muito recentemente não atrativos para os interesses estratégicos do desenvolvimento capitalista -, como, por exemplo, o artesanato, pequenas cidades do Nordeste e as chamadas "comunidades tradicionais" - inaugurando o que a autora denomina aqui, provisoriamente, de empresariamento "cultural".

$\mathrm{Na}$ avaliação da autora, o avanço no país de estratégias de desenvolvimento, que visam a transformar locais não atrativos para os interesses estratégicos do desenvolvimento capitalista em locais atrativos para esses interesses, pode levar à 
desintegração/apagamento de "culturas" e, consequentemente, resultar em sérios problemas para aqueles que nelas ou sob sua influência vivem, como o comprovam diversos relatos de pessoas que residem nos mesmos, em pesquisas e eventos realizadas recentemente.

\section{Mas o que se entende por cultura?}

Com base em Laraia (2009), pode-se afirmar que o interesse nos costumes e modos de comportamento dos diferentes povos do mundo é muito antigo. Heródoto (484-424 a.C.), o grande historiador grego, já o manifesta, quando se surpreende ao estudar o sistema social dos lícios, considerando seus costumes diferentes de todas as outras nações do mundo.

Também são antigas as teorias que tentam explicar as diferenças entre esses costumes e modos de comportamento, associando-as a determinantes biológicos ou geográficos.

Mas o conceito de cultura surge somente entre o final do século XVIII e início do XIX, quando Edward Tylor sintetiza no vocábulo inglês culture, o termo germânico Kultur - utilizado para simbolizar todos os aspectos espirituais de uma comunidade -, e a palavra francesa civilization, que se referia, sobretudo, às realizações materiais de um povo.

A síntese de Tylor resulta na definição de cultura como o "todo complexo que inclui conhecimentos, crenças, arte, moral, leis, costumes ou qualquer outra capacidade ou hábito adquiridos pelo homem como membro de uma sociedade" (TYLOR, 1871, apud LARAIA, 2009: 25). 
Desde então, tem início um grande debate em torno do conceito, o qual, segundo Santos (2003), até a década de 1980, referia-se, por um lado, a repositório do que de melhor foi pensado e produzido pela humanidade e, por outro, a totalidades complexas que se confundem com a sociedade, permitindo caracterizar modos de vida baseados em condições materiais e simbólicas. Tornando-se, a partir dessa década, estratégico para a definição de identidades e de alteridades no mundo, um recurso para a afirmação da diferença e da exigência do seu reconhecimento e um campo de lutas e contradiçôes.

Além da definição de Tylor e das ideias de Santos, cabe destacar, também, como referências importantes para o entendimento dos significados do termo cultura, os antropólogos funcionalistas Bronislaw Malinowski e Reginald Radcliffe Brown, que defendiam a ideia de que as necessidades de alimento, abrigo, reprodução e defesa são respondidas nas formações sociais por modos peculiares de vida, por um sistema singular de instituições inter-relacionadas e que funcionam conjuntamente. E, ainda, Clifford Geertz, que concebe cultura como uma "teia de significados" que o homem tece ao seu redor e que o amarra. Nas palavras do autor:

O conceito de cultura que eu defendo (...) é essencialmente semiótico. Acreditando, como Max Weber, que o homem é um animal amarrado a teia de significados que ele mesmo teceu, assumo a cultura como sendo essas teias e a sua análise; portanto, não como uma ciência experimental em busca de leis, mas como uma ciência interpretativa à procura do significado. (GEERTZ, 1989, p. 15). 
Portanto, por cultura, pode-se entender: costumes, modos de comportamento e modos peculiares de vida; todos complexos e sistemas singulares de instituições inter-relacionadas e que funcionam conjuntamente; teias de significado tecidas pelos homens; o que de melhor foi pensado e produzido pela humanidade; um recurso para a afirmação da diferença e da exigência do seu reconhecimento; um campo de lutas e contradições.

Para fins da reflexão proposta nesse trabalho, no entanto, cultura será entendida, com base nas ideias e conceitos de Malinowski e Radcliffe-Brown, Tylor, Weber e Geertz, como modo de viver de um grupo - constituído com base em costumes, crenças, conhecimentos, valores e códigos de conduta, herdados das gerações anteriores e/ou reconhecidos socialmente como relevantes -, que organiza e dá sentido a existência das pessoas que o compóem. Este é o conceito da autora.

\section{Desenvolvimento: abordagens e conceitos}

O debate sobre desenvolvimento talvez seja mais intenso e controverso do que o debate sobre o conceito de cultura.

Segundo OLIVEIRA (2002), o tema ganha importância a partir da Segunda Guerra Mundial, com a necessidade dos países nela envolvidos de livrar o mundo e, sobretudo, seus próprios territórios, dos problemas que os perseguiam nos períodos anteriores: guerra, desemprego, miséria, discriminação racial, desigualdades políticas, econômicas e sociais.

Os níveis elevados de conforto e de qualidade de vida alcançados pelas nações mais industrializadas do planeta, 
como Estados Unidos e Inglaterra, no pós-guerra, somados à constatação de que o crescimento concentrou-se em alguns centros, acentuando as desigualdades entre países, regiões e pessoas, aumentaram ainda mais a importância do tema.

Pode-se dizer que, em um primeiro momento, desenvolvimento foi associado a crescimento ou a desenvolvimento econômico. Aponta-se a existência de duas correntes de pensamento econômico sobre o tema (SOUZA, 1993, apud OLIVEIRA, 2002): a primeira encara o crescimento econômico como sinônimo de desenvolvimento econômico - nessa corrente estão os modelos de crescimento da tradição clássica e neoclássica; a segunda considera que o crescimento econômico é condição indispensável para o desenvolvimento econômico, mas não é condição suficiente - nesta corrente estão os economistas de orientação crítica, formados na tradição marxista ou cepalina, que conceitua o crescimento como uma simples variação quantitativa do produto, enquanto desenvolvimento é caracterizado por mudanças qualitativas no modo de vida das pessoas, nas instituições e nas estruturas produtivas.

Ao longo do tempo, no campo da economia, a constatação de que o crescimento econômico e a acumulação desenfreada não se faziam acompanhar de desenvolvimento econômico, gerou a preocupação com o caráter sustentável do desenvolvimento. Percebeu-se que as gerações futuras não teriam as mesmas condições e recursos naturais para se desenvolver do que a geração atual, devido ao impacto que a acumulação desenfreada gera sobre o meio ambiente. E criou-se o conceito de desenvolvimento sustentável. 
A ideia de desenvolvimento sustentável está focada na necessidade de promover o desenvolvimento econômico, satisfazendo as "necessidades do presente, sem comprometer a capacidade das novas gerações atenderem as suas próprias necessidades" (COMISSÃO MUNDIAL SOBRE MEIO AMBIENTE E DESENVOLVIMENTO, 1991, p.46).

Mas se o tema desenvolvimento vem sendo associado, predominantemente, a crescimento e desenvolvimento econômico, isto não quer dizer que não existam outras abordagens sobre o tema.

Ainda na década de 70, Furtado (1974, p.75) afirma:

a idéia de desenvolvimento econômico é um simples mito. Graças a ela tem sido possível desviar as atenções da tarefa básica de identificação das necessidades fundamentais da coletividade e das possibilidades que abrem ao homem os avanços da ciência, para concentrá-las em objetivos abstratos, como são os investimentos, as exportações e o crescimento.

Nas últimas duas décadas, no âmbito do pensamento econômico, o foco da preocupação com os impactos do crescimento econômico se deslocou do meio ambiente para as pessoas. Pensa-se hoje, cada vez mais, se os incrementos positivos no produto e na renda total estão sendo utilizados ou direcionados para promover o desenvolvimento humano, definido por Sen (2000), como a expansão das capacidades das pessoas de exercer, ponderadamente, sua condição de agente e de levar o tipo de vida que valorizam. 
Por outro lado, Wolfe (1991) postula que desenvolvimento deve ser pensado não apenas em termos de desenvolvimento econômico, mas em termos de desenvolvimento social. Ele acredita que seres humanos e seus desejos são capazes de alterar estruturas, de encontrar caminhos entre o que é dado pelas circunstâncias de tempo, lugar e cultura e o que é possível fazer nesse contexto, através do poder da cooperação e da escolha social.

Uma outra abordagem sobre desenvolvimento, encontra-se no Relatório da Comissão Mundial de Cultura e Desenvolvimento da UNESCO, formada por um grupo independente de importantes economistas, cientistas sociais, artistas e pensadores, sob a coordenação do ex-secretário geral das Nações Unidas, Javier Pérez de Cuéllar, publicado em 1997. Qual seja:

O desenvolvimento divorciado do seu contexto humano e cultural não é mais do que um crescimento sem alma. O desenvolvimento econômico, em sua plena realização, constitui parte da cultura de um povo. Essa ideia, contudo, não é comumente aceita. A visão convencional trata a cultura como fato catalisador ou como obstáculo ao desenvolvimento econômico (...) a tese contida nesse relatório é a de que desenvolvimento compreende não apenas o acesso a bens e serviços, mas também a possibilidade de escolher um estilo de coexistência satisfatório, pleno e agradável. Os bens e serviços presentes na visão convencional e estreita do desenvolvimento só têm valor porque contribuem para nossa liberdade de viver de acordo 
com nossos próprios valores. A cultura, por conseguinte, mesmo tendo em vista sua importância como instrumento do desenvolvimento (ou obstáculo a ele), não pode, em última instância, ser reduzida à posição subsidiária de mera promotora (ou freio) do crescimento econômico. $\mathrm{O}$ papel da cultura não se esgota no de servir a certas finalidades - embora o conceito, em seu sentido estrito, possa ter efetivamente essa função; constitui, de forma mais ampla, o fundamento social das próprias finalidades (...). ,

Ao contrário do meio ambiente físico, onde não poderíamos ousar aprimorar o que a natureza já fornece de forma perfeita, a cultura é fonte permanente de progresso e de criatividade. Quando tivermos superado nossa visão do papel instrumental da cultura, e tivermos reconhecido seu papel construtivo, constitutivo e criativo, teremos de pensar o desenvolvimento de maneira a englobar o crescimento cultural" (Nossa Diversidade Criadora, 1997, p.21-22).

A autora concorda com as ideias de Furtado, Wolfe, Sen e do Relatório da Comissão Mundial de Cultura e Desenvolvimento da UNESCO. E, para fins da reflexão proposta nesse trabalho, entende por desenvolvimento: um processo social e não econômico, um processo que deve levar à ampliação das capacidades das pessoas e dos grupamentos humanos de, ponderadamente, definir e tentar levar o tipo de vida que valorizam. Um processo não divorciado do seu contexto humano e cultural. Um processo com alma. 


\section{Desenvolvimento em locais nos quais a(s) cultura(s) não esteja(m) submetida(s) à lógica capitalista: posicionamento}

Como dito na introdução ao texto, sua finalidade consistia em apresentar os seguintes subsídios para a construção de posicionamentos teóricos criteriosos sobre a necessidade e/ ou as possibilidades de desenvolvimento em locais ainda não inseridos, de forma competitiva, nos espaços econômicos globais ou, em outros termos, em locais nos quais a(s) cultura(s) não esteja $(\mathrm{m})$ completamente submetida(s) à lógica da economia capitalista: (i) conceitos de cultura e concepçóes de desenvolvimento, presentes na literatura sobre o tema; (ii) conceitos de cultura e desenvolvimento adotados pela autora em suas reflexões; (iii) seu posicionamento atual em relação ao assunto.

Uma vez apresentados conceitos de cultura e concepções de desenvolvimento presentes na literatura sobre o tema, uma vez apresentados os conceitos de cultura e desenvolvimento da autora, passa-se a expor seu posicionamento em relação à necessidade e /ou às possibilidades de desenvolvimento em tais locais.

\section{Sobre a necessidade de desenvolvimento}

Considerando as definições de desenvolvimento e cultura adotadas para fins desse trabalho, acredita-se que o desenvolvimento - se entendido como o processo que amplia a capacidade das pessoas e grupos de definir e tentar levar o tipo de vida que valorizam, ponderando sobre os impactos 
de suas escolhas na própria vida e na vida do grupo do qual fazem parte, nos modos de viver que organizam e dão sentido a sua existência - é sempre necessário. E não apenas em locais nos quais a(s) cultura(s) não esteja(m) completamente submetida(s) à lógica e práticas capitalistas - lógicas e práticas que, como afirma Santos (2005), produzem desigualdades de recursos e de poder, formas de sociabilidade empobrecidas, reduzidas ao intercâmbio e ao benefício pessoal produzido pelas relações de concorrência, e esgotamento dos recursos naturais. Mas em todos os locais do planeta.

O problema é como desencadeá-lo, promovê-lo, transformá-lo em resultados satisfatórios para a existência das pessoas e a vida em sociedade.

Quanto à necessidade dos outros tipos de desenvolvimento, apresentados anteriormente com base na literatura sobre o tema, acredita-se que esta deve ser definida a partir da ponderação acima mencionada, por grupos que representem a diversidade de ideias e expectativas presentes nos diversos locais.

\section{Os desenvolvimentos possíveis}

Sobre os desenvolvimentos possíveis em locais nos quais $\mathrm{a}(\mathrm{s})$ cultura(s) não esteja $(\mathrm{m})$ completamente submetida(s) à lógica e práticas capitalistas, acredita-se que estes irão depender dos interesses e da força dos agentes locais e, sobretudo, das lideranças políticas e sociais locais.

Se essas lideranças reconhecerem a importância e valorizarem a cultura local, como definida neste trabalho, os 
processos de desenvolvimento resultarão em modos de viver adequados às características e desejos da população local e na ampliação da capacidade de todos de definir e tentar levar o tipo de vida que valorizam.

Se essas lideranças não reconhecerem a importância e não valorizarem a cultura local, os processos de desenvolvimento poderão resultar na desintegração ou no apagamento de "culturas" e, consequentemente, na desorganização da vida, na perda do sentido da existência e em outros tantos problemas para parcelas da população que sob sua influência vivem; parcelas estas maiores ou menores em função da estratégia adotada.

\section{Considerações Finais}

Diante dessas reflexões, vislumbram-se pelo menos dois cenários distintos para locais nos quais a $(\mathrm{s})$ cultura(s) não esteja $(\mathrm{m})$ completamente submetida(s) à lógica e práticas capitalistas e para as populações que neles vivem.

No primeiro cenário, os locais têm sua cultura reconhecida e valorizada e sua população lugar de agente ou partícipe de processos sociais e políticos, inéditos e criativos, que resultem em modos de viver adequados às suas características, necessidades e desejos.

No segundo cenário, os locais têm elementos de sua cultura identificados como mercadorias vendáveis no mercado capitalista e sua população, lugar de objeto de processos que podem trazer sérios problemas para ela. 
Diante desse contexto, e no sentido de contribuir para que o primeiro cenário se materialize, termina-se esse texto com a informação de que se encontram em elaboração projetos de pesquisa e extensão que têm por finalidade identificar/ construir alternativas de desenvolvimento com base nas culturas locais.

\section{Referências}

AMIN, Ash; ROBINS, Kevin. Regresso das economias regionais? A geografia da acumulação flexível. In: BENKO, Georges; LIPIETZ, Alain. As regióes ganhadoras. Distritos e redes: os novos paradigmas da Geografia Econômica. Oeiras: Celta Editora, 1994. p.77-101.

COMISSÃO MUNDIAL SOBRE MEIO AMBIENTE E DESENVOLVIMENTO. Nosso futuro comum. 2. ed. Rio de Janeiro: Editora da FGV, 1991.

FEDOZZI, Luciano. Orçamento Participativo: reflexões sobre a experiência de Porto Alegre. Porto Alegre: Tomo Empresarial, 1997.

FEDOZZI, Luciano. Práticas inovadoras de gestão urbana: o paradigma participativo. Revista Paranaense de Desenvolvimento, Curitiba, n. 100, p. 93-107, jan./jun. 2001.

FURTADO, Celso. O mito do desenvolvimento econômico. São Paulo: Círculo do Livro, 1974. 
GEERTZ, C. A interpretação das culturas. Rio de Janeiro: Guanabara, 1989.

HARVEY, David. Do gerenciamento ao empresariamento: a transformação da administração urbana no capitalismo tardio. São Paulo, Espaço e Debates, n. 39, p. 48-64, 1996.

LARAIA, Roque de Barros. Cultura: um conceito antropológico. 14. ed. Rio de Janeiro: Jorge Zahar Ed., 2001.

LLORENS, F. A. Desenvolvimento econômico local. Caminhos e desafios para a construção de uma nova agenda política. Rio de Janeiro: BNDES, 2001.

NOSSA DIVERSIDADE CRIADORA: Relatório da Comissão Mundial de Cultura e Desenvolvimento. Campinas, SP: Papirus; Brasília: UNESCO, 1997.

OLIVEIRA, Gilson Batista. Uma discussão sobre o conceito de desenvolvimento. Revista FAE, Curitiba, v.5, p.37-48, maio/ago. 2002.

OSBORNE, David; GAEBLER, Ted. Reinventando o governo: como o espírito empreendedor está transformando o setor público. 6a ed. Brasília: MH Comunicação, 1995.

SANTOS, Boaventura de Sousa; NUNES, João Arriscado. Introdução: para ampliar o cânone do reconhecimento, da diferença e da igualdade. In: SANTOS, Boaventura de Sousa. Reconhecer para libertar: os caminhos do cosmopolitismo multicultural. Rio de Janeiro: Civilização Brasileira, 2003. p. 25-68. 
SEN, Amartya. Desenvolvimento como liberdade. São Paulo: Companhia das Letras, 2000.

WOLFE, A. Três caminhos para o desenvolvimento: mercado, estado e sociedade civil. In: A democracia como proposta. Rio de Janeiro: IBASE, 1991. p. 35-63. 